\title{
Amycolatopsis camponoti sp. nov., new tetracenomycin-producing actinomycete isolated from carpenter ant Camponotus vagus
}

\author{
Yuliya V. Zakalyukina ${ }^{\circledR} \cdot$ Ilya A. Osterman ${ }^{\circledR}$ - \\ Jacqueline Wolf $\mathbb{D} \cdot$ Meina Neumann-Schaal $\mathbb{D}$. \\ Imen Nouioui ${ }^{(1)} \cdot$ Mikhail V. Biryukov $(\mathbb{D}$
}

Received: 15 November 2021 / Accepted: 30 January 2022 / Published online: 26 February 2022

(C) The Author(s) 2022, corrected publication 2023

\begin{abstract}
An actinobacterial strain A23 ${ }^{\mathrm{T}}$, isolated from adult ant Camponotus vagus collected in Ryazan region (Russia) and established as tetracenomycin $\mathrm{X}$ producer, was subjected to a polyphasic taxonomic study. Morphological characteristics of this strain included well-branched substrate mycelium and aerial hyphae fragmented into rod-shaped elements. Phylogenetic analyses based on 16S rRNA gene and genome sequences showed that strain A23 ${ }^{\mathrm{T}}$ was most closely related to Amycolatopsis pretoriensis DSM $44654^{\mathrm{T}}$. Average nucleotide identity and digital DNA-DNA hybridization values between the genome sequences of isolate $\mathrm{A} 23^{\mathrm{T}}$ and its closest relative, Amycolatopsis pretoriensis DSM $44654^{\mathrm{T}}$, were $39.5 \%$ and $88.6 \%$, which were below the $70 \%$ and $95-96 \%$ cut-off point recommended for bacterial
\end{abstract}

Supplementary Information The online version contains supplementary material available at https://doi. org/10.1007/s10482-022-01716-w.

Y. V. Zakalyukina $(\bowtie) \cdot$ I. A. Osterman · M. V. Biryukov Scientific Center of Genetics and Life Sciences, Sirius University of Science and Technology, Sochi, Russia 354340

e-mail: juline@soil.msu.ru

Y. V. Zakalyukina

Department of Soil Science, Lomonosov Moscow State University, Moscow, Russia 119991

I. A. Osterman

Skolkovo Institute of Science and Technology, Skolkovo, Moscow Region, Russia 143025 species demarcation, respectively. The genome size of the isolate $\mathrm{A} 23^{\mathrm{T}}$ was $10,560,374$ bp with a DNA $\mathrm{G}+\mathrm{C}$ content of $71.2 \%$. The whole-cell hydrolysate contained meso-diaminopimelic acid and arabinose and galactose as main diagnostic sugars as well as ribose and rhamnose. It contained MK-9(H4) as the predominant menaquinone and iso- $\mathrm{C}_{16: 0}$, iso- $\mathrm{C}_{15: 0}$, anteiso- $\mathrm{C}_{17: 0}$ and $\mathrm{C}_{16: 0}$ as the major cellular fatty acids. Diphosphatidylglycerol and phosphatidylethanolamine prevailed among phospholipids. Mycolic acids were not detected. Based on the phenotypic, genomic and phylogenetic data, isolate $\mathrm{A} 23^{\mathrm{T}}$ represents a novel species of the genus Amycolatopsis, for which the name Amycolatopsis camponoti sp. nov. is proposed, and the type strain is $\mathrm{A} 23^{\mathrm{T}}$ (=DSM $111725^{\mathrm{T}}=$ VKM $2882^{\mathrm{T}}$ ). 
Keywords Amycolatopsis camponoti sp. nov. · Actinobacteria $\cdot$ Amycolatpsis $\mathrm{sp} \cdot$ Tetracenomycin $\mathrm{X} \cdot$ Camponotus vagus

\section{Introduction}

The genus Amycolatopsis Lechevalier et al. 1986 belonged to the family Pseudonocardiaceae Embley et al. 1989 (order Pseudonocardiales Labeda and Goodfellow 2015, class Actinomycetia Salam et al. 2020 (Salam et al. 2020), phylum Actinomycetota corrig. Goodfellow 2021 (Oren and Garrity 2021)), and encompasses 85 validly published species names with Amycolatopsis orientalis as its type species (https://lpsn.dsmz.de/genus/amycolatopsis). Amycolatopsis is aerobic to facultatively anaerobic and characterized by branched vegetative hyphae that undergo fragmentation into rod-like and squarish elements. Whole-cell hydrolysates are rich in meso-2,6-diaminopimelic acid, along with arabinose and galactose as whole-cell sugars. The peptidoglycan is of the A1g type. Muramic acid moieties are $\mathrm{N}$-acetylated. Does not contain mycolic acids. The diagnostic phospholipid is phosphatidylethanolamine and/or phosphatidylmethylethanolamine while the occurrence of diphosphatidylglycerol, phosphatidylglycerol, phosphatidylinositol and phosphatidylinositol mannosides is variable (Tan and Goodfellow 2015). Amycolatopsis have been described from diverse environments such as soil, vegetation, human and animal clinical sources, fresh water, rock and subterranean sites (Lee 2009).

The 16S rRNA gene phylogeny provides a useful framework for inferring the relationships between genera in the Pseudonocardiaceae family, but did not seem to have enough taxonomic resolution to distinguish species. The use of multi-locus sequence analysis (MLSA) is able to clarify the taxonomic positions of Amycolatopsis species (Glaeser and Kämpfer 2015). The most reliable way to identify actinobacteria strains is the comparison of genomes from the point of view of DNA-DNA relatedness and construction whole-genome phylogenetic trees (Nouioui et al. 2018).

The studies of 66 publicly available representative genome sequences of Amycolatopsis type strains (https://www.ncbi.nlm.nih.gov/genome/browse\# !/prokaryotes/Amycolatopsis) have revealed that
Amycolatopsis have comparatively large genomes from nearly 5.62 Mb (Amycolatopsis granulosa DSM $45669^{\mathrm{T}}$ ) to $10.94 \mathrm{Mb}$ (Amycolatopsis anabasis EGI $650086^{\mathrm{T}}$ ), GC content from $67.8 \%$ (Amycolatopsis palatopharingis DSM $44832^{\mathrm{T}}$ ) to $72.7 \%$ (Amycolatopsis arida DSM $45648^{\mathrm{T}}$ ), while median genome size and DNA G $+\mathrm{C}$ content are $9.08 \mathrm{Mb}$ and $70.1 \%$, respectively. The circular chromosomes containing over 20 secondary metabolic gene clusters (Kumari et al. 2016).

The genus Amycolatopsis comprises a large group of commercially and medically important actinobacteria capable of producing two major types of antibiotics: glycopeptides and polyketides (Kisil et al. 2021). In this paper, we describe strain $\mathrm{A} 23^{\mathrm{T}}$, isolated from body of ant Camponotus vagus collected in Ryazan region, Russia. This strain is able to produce the aromatic polyketide antibiotic tetracenomycin $\mathrm{X}$ $(\mathrm{TcmX})$ and its new congener 6-hydroxytetracenomycin X (6-OH-Tcm X) which possess antimicrobial and cytotoxic activity (Osterman et al. 2020; Alferova et al. 2021). As recently demonstrated TcmX and 6-OH-Tcm $\mathrm{X}$ are potent inhibitors of protein synthesis due to the fact that they bind to the large subunits of prokaryotic or eukaryotic ribosomes, within the polypeptide exit tunnel (Osterman et al. 2020).

Polyphasic study was used to clarify the taxonomic position of novel strain $A 23^{\mathrm{T}}$. We propose to establish this strain as a representative for the novel species of the genus Amycolatopsis, with the name Amycolatopsis camponoti sp. nov.

\section{Materials and methods}

Collection and microbial isolation

Strain $\mathrm{A} 23^{\mathrm{T}}$ was isolated from bodies of adult workers of Camponotus vagus collected in Kasimovsky District, Ryazan region, Russia (55.01138 N, 41.73078 E) (Zakalyukina et al. 2021). Five individuals were washed three times in sterile distilled water and then crushed by tissue microhomogenizer with sterile saline solution. Aliquots of this mixtures were spread over M490 medium (HiMediaLab) supplemented with nystatin and nalidixic acid at final concentrations of $250 \mu \mathrm{g} / \mathrm{mL}$ and $10 \mu \mathrm{g} / \mathrm{mL}$, respectively, and incubated for 14 days at $28{ }^{\circ} \mathrm{C}$ (Zakalyukina et al. 2019). The strain was purified and maintained on Organic 
medium 79 (Prauser and Falta 1968), and preserved as suspension of mycelial fragments and spores in $20 \%(\mathrm{v} / \mathrm{v})$ glycerol at $-20^{\circ} \mathrm{C}$.

Genome features and phylogenomic analysis

Genome of strain $\mathrm{A} 23^{\mathrm{T}}$ was sequenced de novo by Novogene Co., Ltd. (https://en.novogene.com/), using the Illumina NovaSeq 6000 platform and fully annotated using RAST prokaryotic genome annotation service (https://rast.nmpdr.org/) and submitted in GenBank (assembly accession: GCA_902497555.1) (Osterman et al. 2020).

Average nucleotide identity (ANI) (Rodríguez$\mathrm{R}$ and Konstantinidis 2016) and in silico digital DNA:DNA hybridization (DDH) were calculated using JSpecies WS (http://jspecies.ribohost.com/jspec iesws/), and GGDC method, with the recommended formula 2, available at the TYGS web service, respectively (Meier-Kolthoff and Göker 2019).

Phylogenomic analysis was performed using Type (Strain) Genome Server (https://tygs.dsmz.de/). The phylogenomic tree inferred with FastME 2.1.6.1 (Lefort et al. 2015) from GBDP distances calculated from genome sequences. The branch lengths are scaled in terms of GBDP distance formula d5.

\section{S rRNA phylogeny}

The full-length 16S rRNA gene sequences of strain $\mathrm{A} 23^{\mathrm{T}}$ was extracted from the whole genome sequence (CABVGP010000001.1) and was compared to sequences of type strains in the EzBioCloud database (www.ezbiocloud.net).

Evolutionary trees based on $16 \mathrm{~S}$ rRNA gene sequences were inferred with the neighbour-joining, maximum-parsimony and maximum-likelihood treemaking algorithms after CLUSTAL W alignment by using MEGA software version X (Kumar et al. 2018) (https://www.megasoftware.net). These evolutionary analyzes involved 24 nucleotide sequences. All positions with less than $95 \%$ site coverage were eliminated, i.e., fewer than 5\% alignment gaps, missing data, and ambiguous bases were allowed at any position (partial deletion option). There were a total of 1414 positions in the final dataset.
Phenotypic characterization

Cultural characteristics of strain $\mathrm{A} 23^{\mathrm{T}}$ were observed on the range of ISP 2-ISP 7 media (Shirling and Gottlieb 1966), Organic medium 79 and modified Bennett's agar (Tan et al. 2006b) after cultivation up to 14 days at $28{ }^{\circ} \mathrm{C}$. Cell morphology of strain A23 on Organic medium 79 after cultivation at $28{ }^{\circ} \mathrm{C}$ for 10 days was studied using scanning electron microscopy (JSM-6380LA, JEOL). Motility test was carried out using the "hanging drop" method by light microscope (Fisherbrand AX-502, Thermo Fisher Scientific).

Carbon source utilization was assessed on basal medium ISP 9 (Shirling and Gottlieb 1966) with addition of $0.04 \%$ solution of bromocresol purple at $28{ }^{\circ} \mathrm{C}$ for 14 days. Enzyme activities were estimated using paper indicator system (NPO Microgen, Russia) according to the manufacturer's recommendations at $28{ }^{\circ} \mathrm{C}$ for 7 days. The degradation of casein, starch and cellulose was estimated on clearing of the insoluble compounds around areas of growth (Williams et al. 1983). The ability of strain to grow at a different $\mathrm{pH}(\mathrm{pH} 5.0, \mathrm{pH}$ 6.0, $\mathrm{pH} 7.0, \mathrm{pH}$ 8.0, $\mathrm{pH}$ 9.0) was tested on a modified ISP 9 medium $(\mathrm{g} / \mathrm{L}$ : $\left(\mathrm{NH}_{4}\right)_{2} \mathrm{SO}_{4}-2.64, \quad \mathrm{MgSO}_{4} \times 7 \mathrm{H}_{2} \mathrm{O}-1$, glucose-10, agar-20), buffered with phosphate solutions according to Williams et al. (Williams et al. 1971), at $28{ }^{\circ} \mathrm{C}$ for 14 days. The growth at different range of temperature $\left(5{ }^{\circ} \mathrm{C}, 10{ }^{\circ} \mathrm{C}, 20{ }^{\circ} \mathrm{C}, 30{ }^{\circ} \mathrm{C}, 40{ }^{\circ} \mathrm{C}\right)$ and salinity $(1 \%, 5 \%, 8 \%)$ were assessed on Organic medium 79 after 14 days of incubation.

\section{Chemotaxonomy}

Cell biomass of strains $\mathrm{A} 23^{\mathrm{T}}$ and $A$. pretoriensis DSM $44654^{\mathrm{T}}$ were obtained from cultures grown in DSMZ 554 broth medium and on a rotary shaker (180 r.p.m) at $28^{\circ} \mathrm{C}$. After 120 -h growth cells were centrifuged, washed three times in sterile distilled water and freeze-dried. Whole-cell sugars (Lechevalier and Lechevalier 1970; Staneck and Roberts 1974), menaquinone (Collins et al. 1985) and diaminopimelic acids analyses (Schleifer and Kandler 1972) were carried out. Standard chromatographic procedures were used to determine polar lipid pattern for strain $\mathrm{A} 23^{\mathrm{T}}$ and A. pretoriensis DSM $44654^{\mathrm{T}}$ following the protocol of Minnikin et al. (1984). 
Cellular fatty acids extracts were prepared using minor modifications of the protocol of Miller (Miller 1982) and Kuykendall et al. (Kuykendall et al. 1988). Gas chromatography (Agilent 6890N instrument) was used to analyse the fatty acid methyl esters which were identified using Sherlock Microbial Identification system (MIDI, Microbial ID, Newark, DE 19711 U.S.A.) and the Actin6 database (Sasser 1990). The analysis was supplemented by a GC-MS run on an Agilent GC-MS 7000D for identity confirmation. Mycolic acids extraction was performed according to Vilchéze and Jacobs (Vilcheze and Jacobs 2007). Cell lysis was carried out in $\mathrm{KOH} / \mathrm{MeOH}$ solution at $95{ }^{\circ} \mathrm{C}$ overnight and extracted with chloroform. Dried extracts were recovered in chloroform:MeOH $(9: 1)$ and analyzed in negative ion mode on an Agilent QTof mass spectrometer by direct infusion into the ESI source $(300 \mu \mathrm{L} / \mathrm{min})$. Mycolic acids were identified by comparison of the exact masses of known mycolic acid structures to the measured ones (Bouam et al. 2018).

Analysis of bioactive compound biosynthetic gene clusters and potential pathogenicity

Secondary metabolite biosynthetic gene clusters in complete genome strain $\mathrm{A} 23^{\mathrm{T}}$ (CABVGP010000000) and $A$. pretoriensis DSM $44654^{\mathrm{T}}$ (GenBank Accessions FNUJ01000000) were identified with the bacterial version of antiSMASH 6.1 .0 (https://antismash. secondarymetabolites.org/). Homologous regions on each genome were identified using NCBI Blastn (https://blast.ncbi.nlm.nih).

For predicting the pathogenicity of $\mathrm{A} 23^{\mathrm{T}}$ and closely related strains we used PathogenFinder (http://cge.cbs.dtu.dk/services/PathogenFinder/), a web-server for the prediction of bacterial pathogenicity by analysing the input genome (Cosentino et al. 2013).

\section{Results and discussion}

Amycolatopsis strains are well known as producers for the commercially used antibiotics, e.g. vancomycin, rifamycin, eremomycin (Kisil et al. 2021). Other compounds with antibacterial, antifungal or antiviral properties that have been derived from Amycolatopsis strains are quartromycin, octacosamicin, chelocardin, kigamicin and the macrotermycins A-D (Chen et al. 2016; Kumari et al. 2016; Beemelmanns et al. 2017). It has been shown that there is a relationship between the distribution of biosynthetic gene clusters (BGCs) and phylogenetic lineages in Amycolatopsis genomes. Amycolatopsis strains that produce, or have the potential to produce, a particular class of antibiotic are phylogenetically related (Adamek et al. 2018). Strain $A 23^{T}$ was previously known to produce bioactive compounds (Osterman et al. 2020; Alferova et al. 2021) was subjected to a polyphasic taxonomic approach to clarify its taxonomic position.

Phylogenomic analysis based on whole-genome sequences showed that strain $\mathrm{A} 23^{\mathrm{T}}$ formed a wellsupported monophyletic clade with A. pretoriensis DSM $44654^{\mathrm{T}}$ with $100 \%$ bootstrap value (Fig. 1). The neighbor-joining (Fig. S1), maximum-likelihood (Fig. S2) and maximum-parsimony (Fig. S3) trees based on 16S rRNA full-length gene sequences revealed that strain $\mathrm{A} 23^{\mathrm{T}}$ formed a subclade in the Amycolatopsis tree together with Amycolatopsis pretoriensis DSM $44654^{\mathrm{T}}$ and Amycolatopsis lexingtonensis NRRL B-24131 ${ }^{\mathrm{T}}$, concurrently the similarity detected by EzBioCloud is $99.1 \%$ and $99.2 \%$ respectively. The isolate was also found to share relatively high $16 \mathrm{~S}$ rRNA gene similarities with the type strains of $A$. rifamycinica DSM $46095^{\mathrm{T}}$ (99.3\%), A. kentuckyensis NRRL B-24129 $9^{\mathrm{T}}$ (99.1\%), A. tolypomycina DSM $44544^{\mathrm{T}}$ (98.9\%), A. vancoresmycina DSM $44592^{\mathrm{T}}(98.8 \%)$, A. eburnea NBRC $113658^{\mathrm{T}}$ (98.6\%), A. balhimycina DSM 44591 ${ }^{\mathrm{T}}$ (98.5\%), A. mediterranei NRRL B-3240 ${ }^{\mathrm{T}}(98.4 \%)$, A. vastitatis NRRL B-65279 $(98.3 \%)$ and A. australiensis DSM $44671^{\mathrm{T}}(97.9 \%)$.

Previous phylogenomic analyses revealed that the Amycolatopsis clade is divided into four major phylogenomic subclades (Adamek et al. 2018; Sangal et al. 2018). This study showed that strain $A 23^{T}$ is closely related to type strains within the group B subclades sensu Adamek et al. 2018 and Sangal et al. 2018. The study of Sánchez-Hidalgo with colleagues (Sánchez-Hidalgo et al. 2018) showed 3 major clades and 11 groups. The strains closely related to strain $\mathrm{A} 23^{\mathrm{T}}$ are within subclade AOS, group C sensu Sánchez-Hidalgo et al. 2018. The genome-based phylogenies of Adamek et al. 2018 and Sánchez-Hidalgo et al. 2018 were based on MLSA, while Sangal et al. 2018 and Teo et al 2021 were based on core protein sequences/core-proteome. The phylogenomic analysis 
Fig. 1 Phylogenetic tree based on whole-genome sequences from $\mathrm{A} 23^{\mathrm{T}}$ and 15 Amycolatopsis type strains. Numbers above branches are GBDP pseudo-bootstrap support values $>60 \%$ from 100 replications, with an average branch support of $93.9 \%$. The tree was rooted at the midpoint

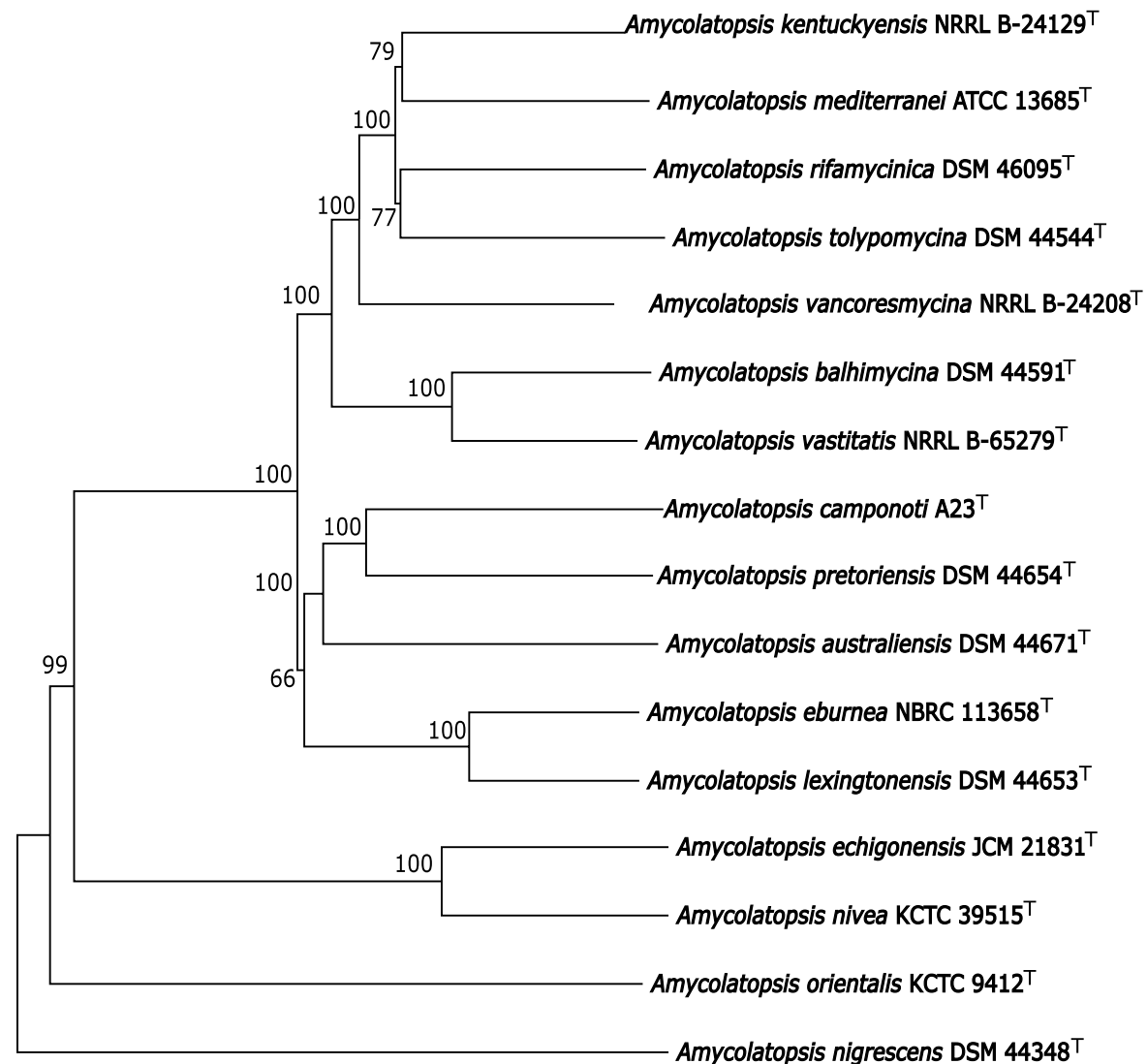

presented in this study, based on GBDP distances calculated from genome sequences, showed consistency with previous studies (Fig. 1).

The complete genome size of strain $\mathrm{A} 23^{\mathrm{T}}$ was $10,560,374$ bp with DNA G + C content of $71.2 \%$, which was consistent with the $\mathrm{G}+\mathrm{C}$ content of the genus Amycolatopsis (Teo et al. 2021). Similar genome features were observed for the closest neighbor A. pretoriensis DSM $44654^{\mathrm{T}}$ (genome size 10,299,026 bp and $\mathrm{G}+\mathrm{C}$ content $71.2 \%$ ). Representatives of the group $\mathrm{B}$ are characterized by the presence of a high number of biosynthetic gene clusters ranged from 28 to 41 per genome (Adamek et al. 2018). That fact explains the ability of majority of this clade to produce antibiotics and/or bioactive molecules (Tan and Goodfellow 2015). The genome properties of strain $\mathrm{A} 23^{\mathrm{T}}$ and other type strains within group B sensu Adamek et al. 2018 and Sangal et al. 2018 are summarized in Table 1.

The ANI and in silico DDH values between strain $\mathrm{A} 23^{\mathrm{T}}$ and strain DSM $44654^{\mathrm{T}}$ were $39.5 \%$ and $88.6 \%$, respectively. The ANI and in silico DDH values between strain $\mathrm{A} 23^{\mathrm{T}}$ and other related species of the genus Amycolatopsis were below the recommended thresholds of $95-96 \%$ and $70 \%$ for species demarcation (Ciufo et al. 2018; Meier-Kolthoff and Göker 2019) (Table S1).

Cells of strain $\mathrm{A} 23^{\mathrm{T}}$ were aerobic, Gram-positive, non-motile. This strain showed a good growth on ISP 2-ISP 5 and moderate on both ISP 6 and ISP 7. The colours of substrate mycelia varied from light ivory to sulfur yellow while aerial hyphae usually were white or cream (Table 2). The branching mycelia (diameter $0.42 \mu \mathrm{m}$ ) fragmented into different lengths rod-shaped elements (Fig. 2), which is typically observed for Amycolatopsis (Franco and Labeda 2014).

Strain $\mathrm{A} 23^{\mathrm{T}}$, as well as its closely related A. australiensis DSM $44671^{\mathrm{T}}$, A. balhimycina DSM $44591^{\mathrm{T}}$, A. eburnea $\mathrm{NBRC} 113658^{\mathrm{T}}$, A. kentuckyensis NRRL B-24129 ${ }^{\mathrm{T}}$, A. lexingtonensis NRRL B-24131 ${ }^{\mathrm{T}}$, A. mediterranei NRRL B-3240 ${ }^{\mathrm{T}}$, A. pretoriensis DSM 


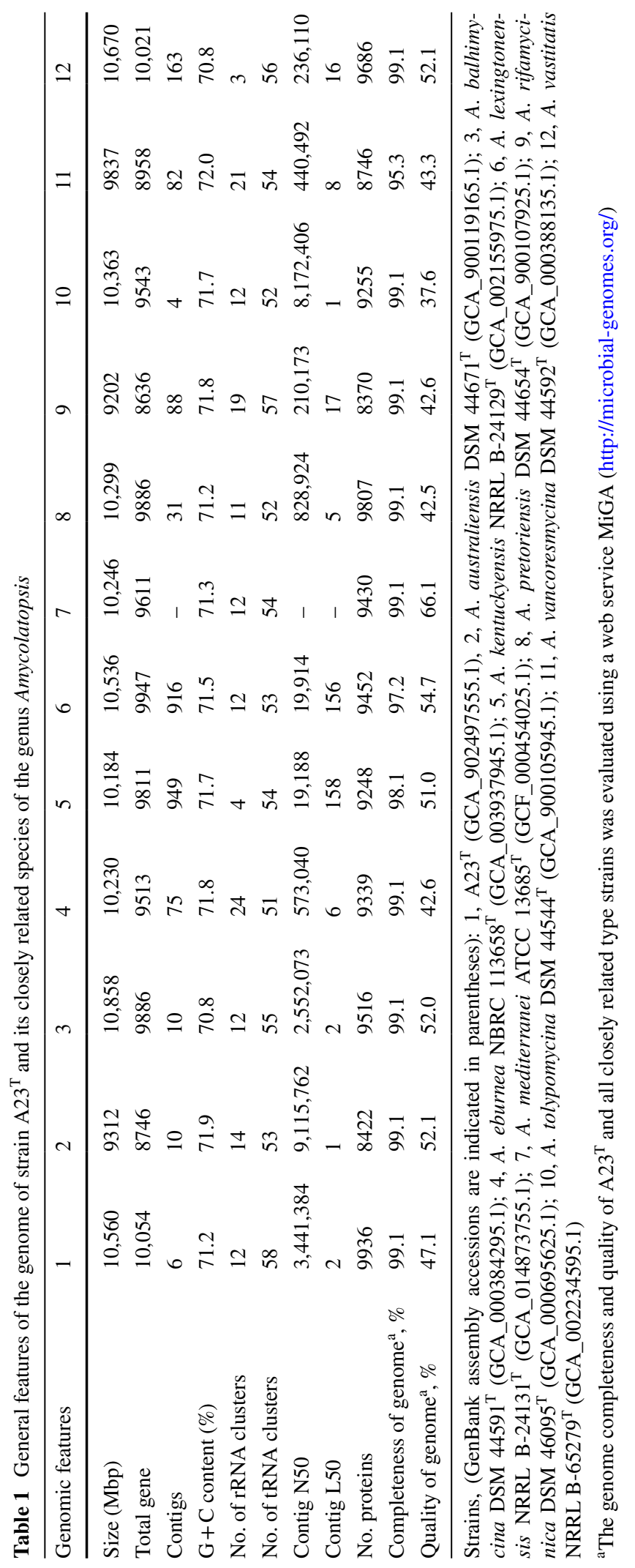


Table 2 Growth and cultural characteristics of Amycolatopsis isolate A23 ${ }^{\mathrm{T}}$ after incubation for 14 days at $28^{\circ} \mathrm{C}$

\begin{tabular}{lllll}
\hline Media & Growth & Aerial spore-mass & Substrate mycelia colour & Soluble pigment \\
\hline Yeast extract-malt extract (ISP 2) & Good & White (9012) & Beige (1001) & None \\
Oatmeal (ISP 3) & Very good & White (9012) & Honey yellow (1005) & None \\
Inorganic salts-starch (ISP 4) & Good & White (9012) & Light ivory (1015) & None \\
Glycerol-asparagine (ISP 5) & Good & Cream (9001) & Beige (1001) & Luminous bright orange (2007) \\
Peptone-yeast extract iron (ISP 6) & Moderate & White (9012) & Sun yellow (1037) & Sun yellow (1037) \\
Tyrosine (ISP 7) & Moderate & Cream (9001) & Sulfur yellow (1016) & Sulfur yellow (1016) \\
Organic medium 79 & Good & White (9012) & Sun yellow (1037) & Sun yellow (1037) \\
Modified Bennett's agar & Good & White (9012) & Suffon yellow (1017) & Suffon yellow (1017) \\
\hline
\end{tabular}

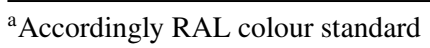

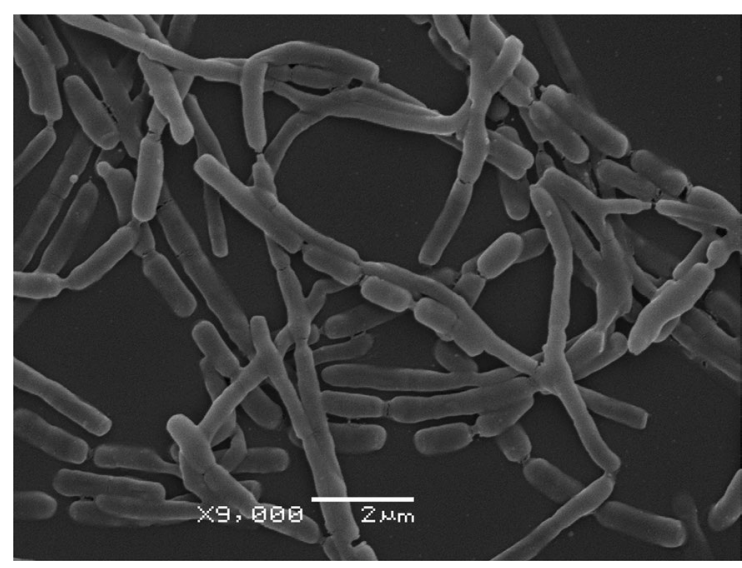

Fig. 2 Scanning electron micrograph of strain $A 23^{\mathrm{T}}$, showing aerial mycelium that fragmented into rod-shaped elements after incubation on Organic medium 79 at $28{ }^{\circ} \mathrm{C}$ for 10 days

$44654^{\mathrm{T}}$, A. rifamycinica DSM $46095^{\mathrm{T}}$, A. tolypomycina DSM $44544^{\mathrm{T}}$, A. vancoresmycina DSM $44592^{\mathrm{T}}$, A. vastitatis NRRL B-65279 ${ }^{\mathrm{T}}$, produced acid from glucose and inositol. All the above mentioned strains were capable of peptonization of gelatin (Table 3 ). The majority of considered strains including strain $\mathrm{A} 23^{\mathrm{T}}$ were able to utilize arabinose, fructose, galactose, sucrose and decompose of urea. They grew at $30{ }^{\circ} \mathrm{C}$ and in the presence of $\mathrm{NaCl} 1 \% \mathrm{w} / \mathrm{v}$, but none produced amylases. The optimum growth temperature and $\mathrm{pH}$ of strain $\mathrm{A} 23^{\mathrm{T}}$ were $28-30{ }^{\circ} \mathrm{C}$ and $\mathrm{pH}$ 7 , accordingly, but it was able to grow between $\mathrm{pH}$ 6.0-9.0 and up to $\mathrm{NaCl} 5.0 \%(\mathrm{w} / \mathrm{v})$.

The whole-cell hydrolysates of strain $\mathrm{A} 23^{\mathrm{T}}$ contained meso-2,6-diaminopimelic acid, arabinose, galactose, ribose and a trace of rhamnose as wholecell sugars. However, strain DSM $44654^{\mathrm{T}}$ had arabinose and galactose as the major cell sugars while ribose and rhamnose were present in traces. No mycolic acid was detected. Both strains showed similar isoprenoid quinone profile with MK-9(H4) as the predominant one (Table S3). The major fatty acids $(>10 \%)$ for strain $\mathrm{A}_{2} 3^{\mathrm{T}}$ were iso- $\mathrm{C}_{16: 0}$, iso$\mathrm{C}_{15: 0}$, anteiso- $\mathrm{C}_{17: 0}$ and $\mathrm{C}_{16: 0}$ while the type strain of $A$. pretoriensis species had iso- $\mathrm{C}_{16: 0}$ and iso- $\mathrm{C}_{15: 0}$ (Table S4). The polar lipid pattern of $\mathrm{A} 23^{\mathrm{T}}$ included diphosphatidylglycerol, phosphatidylethanolamine (diagnostic lipid), aminophospholipid, a glycolipid, phospholipid and unidentified lipids (Fig. S6), as well as for strain DSM $44654^{\mathrm{T}}$ (Fig. S7).

Online tool antiSMASH predicted 32 secondary metabolite gene clusters in the genome of strain $\mathrm{A} 23^{\mathrm{T}}$ (Table S5) and 30 ones in A. pretoriensis (Table S6). In total, from $\mathrm{A} 23^{\mathrm{T}}$ genome it was identified $11 \mathrm{PKS}$ clusters, 10 NRPS and gene NRPS-like clusters, 2 RiPPs and 4 terpenes, while from DSM $44654^{\mathrm{T}}$ there were 10, 10, 2 and 4 accordingly.

The genome mining of strain $\mathrm{A} 23^{\mathrm{T}}$ revealed that this strain has the potential to produce wide range of secondary metabolites including limazepines A, C-F and macrotermycins A-D (Table S5). The limazepines belong to the growing group of the pyrrolo[1,4]benzodiazepine antitumor antibiotics. Their inherent antitumor and antibacterial activities are due to their ability to regulate gene expression by recognizing and binding with DNA GC base pairs (Fotso et al. 2009). These limazepines' clusters were identical to that in strain Streptomyces sp. ICBB 8177, and showed also $82 \%$ of genes similarity with the sequence of tomaymycin in strain Streptomyces achromogenes (Li et al. 2009) (Fig. 3). Macrotermycin biosynthetic gene clusters with $96 \%$ similarity to that of Amycolatopsis 
Table 3 Differential characteristics of strain $\mathrm{A} 23^{\mathrm{T}}$ and its closely related species of Amycolatopsis

The strains were listed in the same order as in Table 1: + , positive; - , negative; w, weakly; n/d, not determined

${ }^{\mathrm{a}}$ The data were obtained experimentally

${ }^{\mathrm{b}}$ The sources were used for: 2, A. australiensis DSM $44671^{\mathrm{T}}$ (Tan et al. 2006a); 3, A. balhimycina DSM $44591^{\mathrm{T}}$, 10, A. tolypomycina DSM $44544^{\mathrm{T}}, 11$,

A. vancoresmycina DSM $44592^{\mathrm{T}}$ (Wink et al. 2003); 4, A. eburnea NBRC $113658^{\mathrm{T}}$ (Chaiya et al. 2019); 5, A. kentuckyensis NRRL B-24129 ${ }^{\mathrm{T}}$,

6, A. lexingtonensis

NRRL B-24131 ${ }^{\mathrm{T}}$,

8, A. pretoriensis

DSM $44654^{\mathrm{T}}$ (Labeda et al. 2003); 7, A. mediterranei ATCC $13685^{\mathrm{T}}$

(Lechevalier et al. 1986); 9, A. rifamycinica DSM $46095^{\mathrm{T}}$ (Bala et al. 2004); 12, A. vastitatis NRRL B-65279 ${ }^{\mathrm{T}}$ (Idris et al. 2018)

\begin{tabular}{|c|c|c|c|c|c|c|c|c|c|c|c|c|}
\hline Property & $1^{\mathrm{a}}$ & $2^{b}$ & $3^{b}$ & $4^{b}$ & $5^{\mathrm{b}}$ & $6^{b}$ & $7^{\mathrm{b}}$ & $8^{\mathrm{b}}$ & $9^{b}$ & $10^{\mathrm{b}}$ & $11^{\mathrm{b}}$ & $12^{\mathrm{b}}$ \\
\hline \multicolumn{13}{|l|}{ Utilization activity } \\
\hline Adonitol & - & - & $\mathrm{n} / \mathrm{d}$ & + & + & + & - & - & + & $\mathrm{n} / \mathrm{d}$ & $\mathrm{n} / \mathrm{d}$ & $\mathrm{n} / \mathrm{d}$ \\
\hline Arabinose & + & + & + & + & + & + & + & + & + & + & + & $\mathrm{n} / \mathrm{d}$ \\
\hline Cellobiose & $\mathrm{n} / \mathrm{d}$ & + & $\mathrm{n} / \mathrm{d}$ & $\mathrm{n} / \mathrm{d}$ & + & + & + & + & + & $\mathrm{n} / \mathrm{d}$ & $\mathrm{n} / \mathrm{d}$ & $\mathrm{n} / \mathrm{d}$ \\
\hline Fructose & + & + & + & $\mathrm{n} / \mathrm{d}$ & + & + & + & + & $\mathrm{n} / \mathrm{d}$ & + & + & - \\
\hline Galactose & + & + & $\mathrm{n} / \mathrm{d}$ & + & + & + & + & + & + & $\mathrm{n} / \mathrm{d}$ & $\mathrm{n} / \mathrm{d}$ & $\mathrm{n} / \mathrm{d}$ \\
\hline Glucose & + & + & + & + & + & + & + & + & + & + & + & + \\
\hline Inositol & + & + & + & + & + & + & + & + & + & + & + & + \\
\hline Lactose & + & + & $\mathrm{n} / \mathrm{d}$ & + & + & + & + & + & - & - & - & - \\
\hline Maltose & + & + & $\mathrm{n} / \mathrm{d}$ & + & + & + & + & + & - & - & - & $\mathrm{n} / \mathrm{d}$ \\
\hline Mannitol & + & + & + & + & - & $\mathrm{w}$ & + & - & - & + & + & $\mathrm{n} / \mathrm{d}$ \\
\hline Raffinose & $\mathrm{w}$ & + & + & + & + & + & + & + & - & - & + & $\mathrm{n} / \mathrm{d}$ \\
\hline Rhamnose & + & - & + & + & + & + & + & + & - & + & + & $\mathrm{n} / \mathrm{d}$ \\
\hline Salicin & - & $\mathrm{n} / \mathrm{d}$ & $\mathrm{n} / \mathrm{d}$ & $\mathrm{n} / \mathrm{d}$ & + & + & - & + & $\mathrm{n} / \mathrm{d}$ & $\mathrm{n} / \mathrm{d}$ & $\mathrm{n} / \mathrm{d}$ & $\mathrm{n} / \mathrm{d}$ \\
\hline Sorbitol & + & - & - & + & + & - & - & $\mathrm{w}$ & - & $\mathrm{n} / \mathrm{d}$ & $\mathrm{n} / \mathrm{d}$ & $\mathrm{n} / \mathrm{d}$ \\
\hline Sucrose & + & + & + & $\mathrm{n} / \mathrm{d}$ & + & + & + & + & $\mathrm{n} / \mathrm{d}$ & + & + & $\mathrm{n} / \mathrm{d}$ \\
\hline Xylose & + & + & - & + & + & + & + & + & + & - & - & $\mathrm{n} / \mathrm{d}$ \\
\hline \multicolumn{13}{|l|}{ Growth in/at } \\
\hline $1 \% \mathrm{NaCl}$ & + & + & $\mathrm{n} / \mathrm{d}$ & $\mathrm{n} / \mathrm{d}$ & + & + & + & + & + & $\mathrm{n} / \mathrm{d}$ & $\mathrm{n} / \mathrm{d}$ & + \\
\hline $5 \% \mathrm{NaCl}$ & $\mathrm{w}$ & - & $\mathrm{n} / \mathrm{d}$ & $\mathrm{n} / \mathrm{d}$ & + & + & - & + & $\mathrm{w}$ & $\mathrm{n} / \mathrm{d}$ & $\mathrm{n} / \mathrm{d}$ & $\mathrm{w}$ \\
\hline $8 \% \mathrm{NaCl}$ & - & - & $\mathrm{n} / \mathrm{d}$ & $\mathrm{n} / \mathrm{d}$ & - & $\mathrm{n} / \mathrm{d}$ & - & - & - & $\mathrm{n} / \mathrm{d}$ & $\mathrm{n} / \mathrm{d}$ & - \\
\hline $10^{\circ} \mathrm{C}$ & $\mathrm{w}$ & $\mathrm{w}$ & $\mathrm{n} / \mathrm{d}$ & - & $\mathrm{n} / \mathrm{d}$ & $\mathrm{n} / \mathrm{d}$ & + & + & + & $\mathrm{n} / \mathrm{d}$ & $\mathrm{n} / \mathrm{d}$ & - \\
\hline $30^{\circ} \mathrm{C}$ & + & + & $\mathrm{n} / \mathrm{d}$ & + & + & + & + & + & + & $\mathrm{n} / \mathrm{d}$ & $\mathrm{n} / \mathrm{d}$ & + \\
\hline $40^{\circ} \mathrm{C}$ & - & + & $\mathrm{n} / \mathrm{d}$ & + & + & + & + & - & - & $\mathrm{n} / \mathrm{d}$ & $\mathrm{n} / \mathrm{d}$ & + \\
\hline$\beta$-glucosidase & + & + & + & + & $\mathrm{n} / \mathrm{d}$ & $\mathrm{n} / \mathrm{d}$ & $\mathrm{n} / \mathrm{d}$ & $\mathrm{n} / \mathrm{d}$ & $\mathrm{n} / \mathrm{d}$ & + & - & + \\
\hline Arginine dihydrolase & + & $\mathrm{n} / \mathrm{d}$ & - & $\mathrm{n} / \mathrm{d}$ & $\mathrm{n} / \mathrm{d}$ & $\mathrm{n} / \mathrm{d}$ & $\mathrm{n} / \mathrm{d}$ & $\mathrm{n} / \mathrm{d}$ & $\mathrm{n} / \mathrm{d}$ & + & + & - \\
\hline Lysine decarboxylase & + & $\mathrm{n} / \mathrm{d}$ & - & $\mathrm{n} / \mathrm{d}$ & $\mathrm{n} / \mathrm{d}$ & $\mathrm{n} / \mathrm{d}$ & $\mathrm{n} / \mathrm{d}$ & $\mathrm{n} / \mathrm{d}$ & $\mathrm{n} / \mathrm{d}$ & + & + & $\mathrm{n} / \mathrm{d}$ \\
\hline $\begin{array}{l}\text { Ornithine decarboxy- } \\
\text { lase }\end{array}$ & + & $\mathrm{n} / \mathrm{d}$ & - & $\mathrm{n} / \mathrm{d}$ & $\mathrm{n} / \mathrm{d}$ & $\mathrm{n} / \mathrm{d}$ & $\mathrm{n} / \mathrm{d}$ & $\mathrm{n} / \mathrm{d}$ & $\mathrm{n} / \mathrm{d}$ & + & + & $\mathrm{n} / \mathrm{d}$ \\
\hline Citrate utilization & + & $\mathrm{n} / \mathrm{d}$ & + & $\mathrm{n} / \mathrm{d}$ & $\mathrm{n} / \mathrm{d}$ & $\mathrm{n} / \mathrm{d}$ & $\mathrm{n} / \mathrm{d}$ & $\mathrm{n} / \mathrm{d}$ & $\mathrm{n} / \mathrm{d}$ & + & + & $\mathrm{n} / \mathrm{d}$ \\
\hline \multicolumn{13}{|l|}{ Decomposition of } \\
\hline Casein & w & + & $\mathrm{n} / \mathrm{d}$ & $\mathrm{n} / \mathrm{d}$ & + & + & + & + & + & $\mathrm{n} / \mathrm{d}$ & $\mathrm{n} / \mathrm{d}$ & $\mathrm{n} / \mathrm{d}$ \\
\hline Cellulose & - & $\mathrm{n} / \mathrm{d}$ & $\mathrm{w}$ & $\mathrm{n} / \mathrm{d}$ & $\mathrm{n} / \mathrm{d}$ & $\mathrm{n} / \mathrm{d}$ & - & $\mathrm{n} / \mathrm{d}$ & $\mathrm{n} / \mathrm{d}$ & - & + & $\mathrm{n} / \mathrm{d}$ \\
\hline Gelatin & + & + & + & + & + & + & + & + & + & + & + & + \\
\hline Starch & - & - & $\mathrm{n} / \mathrm{d}$ & $\mathrm{n} / \mathrm{d}$ & - & - & - & - & $\mathrm{n} / \mathrm{d}$ & $\mathrm{n} / \mathrm{d}$ & $\mathrm{n} / \mathrm{d}$ & - \\
\hline Urea & + & + & + & $\mathrm{n} / \mathrm{d}$ & + & + & + & $\mathrm{w}$ & + & + & + & + \\
\hline
\end{tabular}

strain sp. M39 (Beemelmanns et al. 2017) were found in the genome of strains $A 23^{\mathrm{T}}$ (Fig. S8). Macrotermycins A-D are 20-membered glycosylated polyketide macrolactams's had antibacterial and also selective antifungal activity and were isolated from a termiteassociated actinomycete, Amycolatopsis sp. M39 (Beemelmanns et al. 2017).

The DSM $44654^{\mathrm{T}}$ genome contained the same clusters encoded limazepines and macrotermycins, supporting the view that phylogenetic similarity implies the presence of closely related biosynthetic pathways (Adamek et al. 2018).

Previously described tetracenomycin biosynthesis gene cluster and its paralogus Tcm2 cluster (Osterman et al. 2020) were detected in 1.7 and 2.5 regions of genome $\mathrm{A} 23^{\mathrm{T}}$ accordingly. Among all related strains A. rifamycinica DSM $46095^{\mathrm{T}}$ and A. balhimycina DSM $44591^{\mathrm{T}}$ have orthologous clusters in their 


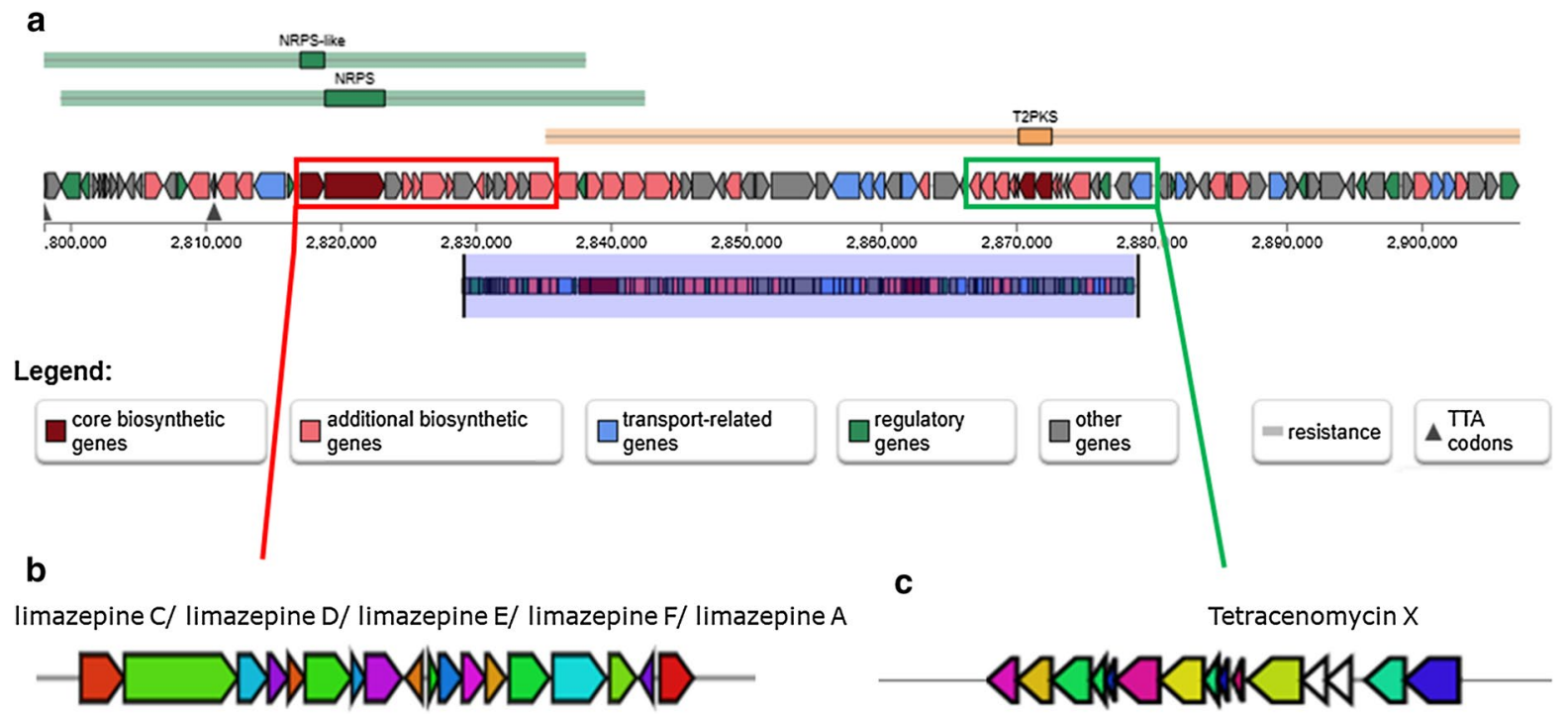

Fig. 3 The BGCs in genome of Amycolatopsis A23 ${ }^{\mathrm{T}}$ A the structure of region 1.7 (location: 2,798,054-2,907,649 nt, total: 109,596 nt); B limazepines cluster of Streptomyces sp. ICBB 8177; C tetracenomycin X biosynthesis cluster

genomes (Osterman et al. 2020). Despite the relatively closeness, no Tcm clusters were detected in the genome sequence of strain DSM $44654^{\mathrm{T}}$ and other related strains.

The vast majority of Amycolatopsis from B-group were predicted as non human pathogen, the values of probability of being a human pathogen were below one (Table S7). Nevertheless, the protein families associated with pathogenicity were detected, so ABCtype transport system protein of Saccharomonospora viridis DSM 43017 was present in the genome of $\mathrm{A} 23^{\mathrm{T}}$ and all the strains examined (Table S7).

Based on phenotypic, phylogenetic and genomics analyses, strain $\mathrm{A} 23^{\mathrm{T}}$, producer of a valuable substance tetracenomycin $\mathrm{X}$, is considered as a type strain of a novel species with the proposed name, Amycolatopsis camponoti.

Description of Amycolatopsis camponoti sp. nov.

Amycolatopsis camponoti (cam.po.no'ti. N.L. gen. n. camponoti of Camponotus, referring to the insect Camponotus vagus Scopoli, from which the type strain was isolated).

Aerobic, Gram-strain-positive, non-motile and filamentous actinobacteria. The aerial mycelia fragments into rod-shaped fragments $(0.42 \mu \mathrm{m}$ in diameter $)$. Well-developed substrate mycelium varies from light ivory to sulfur yellow, and the colour of aerial mycelium usually is white on ISP 2-ISP 4, ISP 6, MBA and Organic 79 media. When growing for three weeks in liquid Organic medium 79, it produces soluble pigments that ranges from faintly brown to red.

The optimum growth temperature and $\mathrm{pH}$ are $28-30{ }^{\circ} \mathrm{C}$ and $\mathrm{pH} 7$, but it is unable to grow at 10 and $40{ }^{\circ} \mathrm{C}$ and out of range $6-9 \mathrm{pH}$ same as above 5.0\% salinity (w/v). It metabolizes arabinose, fructose, galactose, inositol, lactose, maltose, mannitol, rhamnose, sorbitol, sucrose, xylose and weakly raffinose, but unable to use adonitol, cellulose, starch and salicin. Strain $A 23^{\mathrm{T}}$ demonstrates noticeable activity of $\beta$-glucosidase, arginine dihydrolase, lysine and ornithine decarboxylases.

The cell wall contains meso-2,6-diaminopimelic acid, arabinose, galactose, ribose and a trace of rhamnose as cell sugars. Major cellular fatty acids are iso$\mathrm{C}_{16: 0}$, iso- $\mathrm{C}_{15: 0}$, anteiso- $\mathrm{C}_{17: 0}$ and $\mathrm{C}_{16: 0}$. The predominant menaquinone is MK-9(H4), while MK-9(H2) and MK-8(H4) are present as minor components.

The type strain is $\mathrm{A} 23^{\mathrm{T}}\left(=\mathrm{DSM} 111725^{\mathrm{T}}=\mathrm{VKM}\right.$ Ac- $2882^{\mathrm{T}}$ ), isolated from bodies of ants Camponotus vagus in Ryazan region, Russia. The genome size of the isolate $\mathrm{A} 23^{\mathrm{T}}$ is $10,560,374$ bp with a DNA $\mathrm{G}+\mathrm{C}$ content of $71.2 \%$. The GenBank accession number for the $16 \mathrm{~S}$ rRNA gene sequence and the genome 
assembly of strain $\mathrm{A} 23^{\mathrm{T}}$ are $\mathrm{KY} 952635.2$ and GCA_902497555, respectively.

Acknowledgements The authors are indebted to Marlen Jando and Gabriele Pötter (Leibniz Institute DSMZ-German Collection of Microorganisms and Cell Cultures, Braunschweig, Germany) for support with the growth cultures. SEM studies were carried out at the Shared Research Facility "Electron microscopy in life sciences" at Moscow State University (Unique Equipment "Three-dimensional electron microscopy and spectroscopy"). The authors acknowledge partial support from M.V.Lomonosov Moscow State University Program of Development. The authors are grateful to anonymous reviewers for improving the clarity and quality of the manuscript.

Author contributions YVZ carried out the experiments, visualization, analysis the data, and writing draft manuscript, IAO conceptualized the project, JW, MN-S carried out chemotaxonomical assays, IN corrected and reviewed the draft, MVB supervised the project. All authors have read and agreed to the published version of the manuscript.

Funding This research was funded by Sirius University, project [BTH-RND-2127] for YVZ and by Ministry of Science and Higher Education of the Russian Federation (Agreement No 075-15-2021-1085) for IAO, MVB.

Data availability statement The GenBank accession number for the 16S rRNA gene sequence and the genome assembly of strain A23 ${ }^{\mathrm{T}}$ are KY952635.2 and GCA_902497555, respectively. Detailed data on genome analysis $\mathrm{A} 23^{\mathrm{T}}$ are presented IMG/M DataBase (https://gold.jgi.doe.gov/).

\section{Declarations}

Conflict of interest The authors declare no conflict of interest.

Ethical approval This article does not contain any studies with human participants and/or animals performed by any of the authors. The formal consent is not required in this study.

Open Access This article is licensed under a Creative Commons Attribution 4.0 International License, which permits use, sharing, adaptation, distribution and reproduction in any medium or format, as long as you give appropriate credit to the original author(s) and the source, provide a link to the Creative Commons licence, and indicate if changes were made. The images or other third party material in this article are included in the article's Creative Commons licence, unless indicated otherwise in a credit line to the material. If material is not included in the article's Creative Commons licence and your intended use is not permitted by statutory regulation or exceeds the permitted use, you will need to obtain permission directly from the copyright holder. To view a copy of this licence, visit http://creativecommons.org/licenses/by/4.0/.

\section{References}

Adamek M, Alanjary M, Sales-Ortells H et al (2018) Comparative genomics reveals phylogenetic distribution patterns of secondary metabolites in Amycolatopsis species. BMC Genom 19:426. https://doi.org/10.1186/ s12864-018-4809-4

Alferova VA, Maviza TP, Biryukov MV et al (2021) Biological evaluation and spectral characterization of a novel tetracenomycin X congener. Biochimie. https://doi.org/10. 1016/J.BIOCHI.2021.09.014

Bala S, Khanna R, Dadhwal M et al (2004) Reclassification of Amycolatopsis mediterranei DSM 46095 as Amycolatopsis rifamycinica sp. nov. Int J Syst Evol Microbiol 54:1145-1149. https://doi.org/10.1099/ijs.0.02901-0

Beemelmanns C, Ramadhar TR, Kim KH et al (2017) Macrotermycins A-D, glycosylated macrolactams from a termite-Associated Amycolatopsis sp. M39. Org Lett. https:// doi.org/10.1021/acs.orglett.6b03831

Bouam A, Armstrong N, Levasseur A, Drancourt M (2018) Mycobacterium terramassiliense, Mycobacterium rhizamassiliense and Mycobacterium numidiamassiliense sp. nov., three new Mycobacterium simiae complex species cultured from plant roots. Sci Rep 8:9309. https://doi.org/ 10.1038/s41598-018-27629-1

Chaiya L, Matsumoto A, Wink J et al (2019) Amycolatopsis eburnea sp. Nov., an actinomycete associated with arbuscular mycorrhizal fungal spores. Int J Syst Evol Microbiol 69:3603-3608. https://doi.org/10.1099/ijsem.0.003669

Chen S, Wu Q, Shen Q, Wang H (2016) Progress in understanding the genetic information and biosynthetic pathways behind Amycolatopsis antibiotics, with implications for the continued discovery of novel drugs. ChemBioChem 17:119-128. https://doi.org/10.1002/cbic.20150 0542

Ciufo S, Kannan S, Sharma S et al (2018) Using average nucleotide identity to improve taxonomic assignments in prokaryotic genomes at the NCBI. Int J Syst Evol Microbiol 68:2386-2392. https://doi.org/10.1099/ijsem.0. 002809

Collins MD, Goodfellow M, Minnikin DE, Alderson G (1985) Menaquinone composition of mycolic acid-containing actinomycetes and some sporoactinomycetes. J Appl Bacteriol. https://doi.org/10.1111/j.1365-2672.1985.tb014 31. $\mathrm{x}$

Cosentino S, Larsen MV, Aarestrup FM, Lund O (2013) PathogenFinder-distinguishing friend from foe using bacterial whole genome sequence data. PLoS ONE 8:e77302. https://doi.org/10.1371/journal.pone.0077302

Fotso S, Zabriskie TM, Proteau PJ et al (2009) Limazepines A-F, Pyrrolo[1,4]benzodiazepine antibiotics from an Indonesian Micrococcus sp. J Nat Prod. https://doi.org/10. 1021/np800827w

Franco CMM, Labeda DP (2014) The Order Pseudonocardiales. In: The prokaryotes. Springer, Berlin

Glaeser SP, Kämpfer P (2015) Multilocus sequence analysis (MLSA) in prokaryotic taxonomy. Syst Appl Microbiol 38:237-245. https://doi.org/10.1016/J.SYAPM.2015.03. 007

https://lpsn.dsmz.de/genus/amycolatopsis 
Idris H, Nouioui I, Pathom-aree W et al (2018) Amycolatopsis vastitatis sp. nov., an isolate from a high altitude subsurface soil on Cerro Chajnantor, northern Chile. Antonie Van Leeuwenhoek. https://doi.org/10.1007/ s10482-018-1039-3

Kisil OV, Efimenko TA, Efremenkova OV (2021) Looking back to Amycolatopsis: history of the antibiotic discovery and future prospects. Antibiotics. https://doi.org/10.3390/ antibiotics10101254

Kumar S, Stecher G, Li M et al (2018) MEGA X: molecular evolutionary genetics analysis across computing platforms. Mol Biol Evol 35:1547-1549. https://doi.org/10. 1093/molbev/msy096

Kumari R, Singh P, Lal R (2016) Genetics and genomics of the genus Amycolatopsis. Indian J Microbiol 56:233-246. https://doi.org/10.1007/s12088-016-0590-8

Kuykendall LD, Roy MA, O’Neill JJ, Devine TE (1988) Fatty acids, antibiotic resistance, and deoxyribonucleic acid homology groups of Bradyrhizobium japonicum. Int J Syst Bacteriol 38:358-361. https://doi.org/10.1099/00207 713-38-4-358

Labeda DP, Donahue JM, Williams NM et al (2003) Amycolatopsis kentuckyensis sp. nov., Amycolatopsis lexingtonensis sp. nov. and Amycolatopsis pretoriensis sp. nov., isolated from equine placentas. Int J Syst Evol Microbiol 53:1601-1605. https://doi.org/10.1099/ijs.0.02691-0

Lechevalier MP, Lechevalier HA (1970) Chemical composition as a criterion in the classification of aerobic actinomycetes. Int J Syst Evol Microbiol 20:435-443

Lechevalier MP, Prauser H, Labeda DP, Ruan JS (1986) Two new genera of nocardioform actinomycetes: Amycolata gen. nov. and Amycolatopsis gen. nov. Int J Syst Bacteriol 36:29-37. https://doi.org/10.1099/00207713-36-1-29

Lee SD (2009) Amycolatopsis ultiminotia sp. nov., isolated from rhizosphere soil, and emended description of the genus Amycolatopsis. Int J Syst Evol Microbiol 59:14011404. https://doi.org/10.1099/ijs.0.006577-0

Lefort V, Desper R, Gascuel O (2015) FastME 2.0: A Comprehensive, Accurate, and Fast Distance-Based Phylogeny Inference Program. Mol Biol Evol 32:2798-2800. https:// doi.org/10.1093/molbev/msv150

Li W, Chou S, Khullar A, Gerratana B (2009) Cloning and characterization of the biosynthetic gene cluster for tomaymycin, an SJG-136 monomeric analog. Appl Environ Microbiol. https://doi.org/10.1128/AEM.02325-08

Meier-Kolthoff JP, Göker M (2019) TYGS is an automated high-throughput platform for state-of-the-art genomebased taxonomy. Nat Commun 10:2182. https://doi.org/ 10.1038/s41467-019-10210-3

Miller LT (1982) Single derivatization method for routine analysis of bacterial whole-cell fatty acid methyl esters, including hydroxy acids. J Clin Microbiol 16:584-586

Minnikin DE, O'Donnell AG, Goodfellow M, et al (1984) An Integrated Procedure for the extraction of bacterial isoprenoid quinones and polar lipids. J Microbiol Methods 2:233-241

Nouioui I, Carro L, García-López M et al (2018) Genomebased taxonomic classification of the phylum Actinobacteria. Front Microbiol 9:2007. https://doi.org/10.3389/ fmicb.2018.02007
Oren A, Garrity GMY (2021) Valid publication of the names of forty-two phyla of prokaryotes. Int J Syst Evol Microbiol 71:005056. https://doi.org/10.1099/ijsem.0.005056

Osterman IA, Wieland M, Maviza TP et al (2020) Tetracenomycin $\mathrm{X}$ inhibits translation by binding within the ribosomal exit tunnel. Nat Chem Biol. https://doi.org/10.1038/ s41589-020-0578-x

Prauser H, Falta R (1968) Phagensensibilität, ZellwandZusammensetzung und Taxonomie von Actinomyceten. J Basic Microbiol 8:39-46

Rodríguez-RL, Konstantinidis K (2016) The enveomics collection: a toolbox for specialized analyses of microbial genomes and metagenomes

Salam N, Jiao J-Y, Zhang X-T, Li W-J (2020) Update on the classification of higher ranks in the phylum Actinobacteria. Int J Syst Evol Microbiol 70:1331-1355. https://doi. org/10.1099/ijsem.0.003920

Sánchez-Hidalgo M, González I, Díaz-Muñoz C et al (2018) Comparative genomics and biosynthetic potential analysis of two lichen-isolated Amycolatopsis strains. Front Microbiol 9:1-16. https://doi.org/10.3389/fmicb.2018.00369

Sangal V, Goodfellow M, Blom J et al (2018) Revisiting the taxonomic status of the biomedically and industrially important genus Amycolatopsis, using a phylogenomic approach. Front Microbiol 9:2281. https://doi.org/10. 3389/fmicb.2018.02281

Sasser M (1990) Bacterial identification by gas chromatographic analysis of fatty acids methyl esters (GC-FAME). MIDI Labs Inc, Newark

Schleifer KH, Kandler O (1972) Peptidoglycan types of bacterial cell walls and their taxonomic implications. Bacteriol Rev. https://doi.org/10.1128/br.36.4.407-477.1972

Shirling EB, Gottlieb D (1966) Methods for characterization of Streptomyces species. Int J Syst Bacteriol 16:313-340. https://doi.org/10.1099/00207713-16-3-313

Staneck JL, Roberts GD (1974) Simplified approach to identification of aerobic actinomycetes by thin-layer chromatography. Appl Microbiol. https://doi.org/10.1128/am.28.2. 226-231.1974

Tan GYA, Goodfellow M (2015) Amycolatopsis. In: Bergey's manual of systematics of archaea and bacteria. John Wiley \& Sons, Ltd, pp 1-40

Tan GYA, Robinson S, Lacey E, Goodfellow M (2006a) Amycolatopsis australiensis sp. nov., an actinomycete isolated from arid soils. Int J Syst Evol Microbiol 56:2297-2301. https://doi.org/10.1099/ijs.0.64260-0

Tan GYA, Ward AC, Goodfellow M (2006b) Exploration of Amycolatopsis diversity in soil using genus-specific primers and novel selective media. Syst Appl Microbiol 29:557-569. https://doi.org/10.1016/j.syapm.2006.01.007

Teo WFA, Tan GYA, Li W-J (2021) Taxonomic note on the family Pseudonocardiaceae based on phylogenomic analysis and descriptions of Allosaccharopolyspora gen. nov. and Halosaccharopolyspora gen. nov. Int $\mathbf{J}$ Syst Evolut Microbiol 71:005075. https://doi.org/10.1099/ijsem.0. 005075

Vilcheze C, Jacobs WR (2007) Isolation and analysis of Mycobacterium tuberculosis mycolic acids. Curr Protoc Microbiol 5:10A-3

Williams S, Davies FL, Mayfield C, Khan MR (1971) Studies on the ecology of actinomycetes in soil II. The $\mathrm{pH}$ 
requirements of streptomycetes from two acid soils. Soil Biol Biochem. https://doi.org/10.1016/0038-0717(71) 90014-9

Williams ST, Goodfellow M, Alderson G et al (1983) Numerical classification of streptomyces and related genera. Microbiology 129:1743-1813. https://doi.org/10.1099/ 00221287-129-6-1743

Wink JM, Kroppenstedt RM, Ganguli BN et al (2003) Three new antibiotic producing species of the genus Amycolatopsis, Amycolatopsis balhimycina sp. nov., A. tolypomycina sp. nov., A. vancoresmycina sp. nov., and description of Amycolatopsis keratiniphila subsp. keratiniphila subsp. nov. and A. keratiniphi. Syst Appl Microbiol 26:38-46

Zakalyukina YV, Birykov MV, Lukianov DA et al (2019) Nybomycin-producing Streptomyces isolated from carpenter ant Camponotus vagus. Biochimie. https://doi. org/10.1016/j.biochi.2019.02.010

Zakalyukina YV, Zaytsev AR, Biryukov MV (2021) Study of cellulose-destroying activity of actinobacteria associated with ants. Mosc Univ Biol Sci Bull. https://doi.org/10. 3103/S0096392521010065

Publisher's Note Springer Nature remains neutral with regard to jurisdictional claims in published maps and institutional affiliations. 